\title{
Left Ventricle Noncompaction in a Young Adult
}

\author{
András Mester1', Laura Jáni', Monica Chițu² \\ ${ }^{1}$ Center of Advanced Research in Multimodality Cardiac Imaging, Cardio Med Medical Center, Tîrgu Mureș, Romania \\ 2 Clinic of Cardiology, University of Medicine and Pharmacy, Tîrgu Mureș, Romania
}

\section{CORRESPONDENCE}

Laura Jáni

Str. 22 Decembrie 1989 nr. 76

540124 Tîrgu Mureș, Romania

Tel +40265217333

E-mail: jlaura15@yahoo.com

\section{ARTICLE HISTORY}

Received: 27 August, 2016

Accepted: 8 September, 2016
András Mester • Str. 22 Decembrie 1989 nr. 76, 540124 Tîrgu Mureș, Romania. Tel +40 265217333. E-mail: andras.mester@yahoo.com

Monica Chițu • Str. Gheorghe Marinescu nr. 38, 540139 Tîrgu Mureș, Romania. Tel +40 265215551. E-mail: iuliachitu@yahoo.com
We report the case of a 23-year-old young male adult, without any previous personal or family medical history, who was admitted to our department with excessive fatigue, shortness of breath and a presyncope. The physical examination revealed peripheral edemas and bilateral fine basal crackles, cyanosis and hypotension. The resting ECG showed sinus rhythm, $130 \mathrm{bpm}$, with negative T waves in II, aVF, V4-V6.

Transthoracic echocardiography revealed significant left ventricle (LV) enlargement $(75 / 64 \mathrm{~mm})$, with moderate left atrium (LA, $53 \mathrm{~mm})$ and right ventricle (RV, $44 \mathrm{~mm}$ ) enlargement and significant systolic dysfunction (LV ejection fraction 30\%). LV noncompaction (LVNC) was also revealed by echocardiography (Panel A) with prominent trabeculation of the LV (green arrow) and deep recesses (red arrow), with a relatively mobile $13 / 15 \mathrm{~mm}$ echo-dense mass at the apex of the LV, highly specific for thrombus.

Transesophageal echocardiography (Panel B) identified an apical thrombus (red arrow).

As LVNC is frequently associated with other congenital abnormalities, computed tomography (CT) was performed (Panel C), which revealed a ratio of 2.41 of the noncompacted to compacted layer, with no other structural or coronary artery origin abnormality (Panel D)., ${ }^{1,2}$ The apical thrombus (red arrow) and the mid- and apical segment noncompaction (blue arrows) were also noted.

LVNC is a rare genetic cardiomyopathy, with possible late onset of the symptoms and it has to be considered at any age. ${ }^{3}$ Proper imaging techniques must be used for correct diagnosis, management and prevention of complications.

\section{CONFLICT OF INTEREST}

Nothing to declare.

\section{REFERENCES}

1. Bennett CE, Freudenberger R. The Current Approach to Diagnosis and Management of Left Ventricular Noncompaction Cardiomyopathy: Review of the Literature. Cardio/ Res Pract. 2016;2016:5172308. 

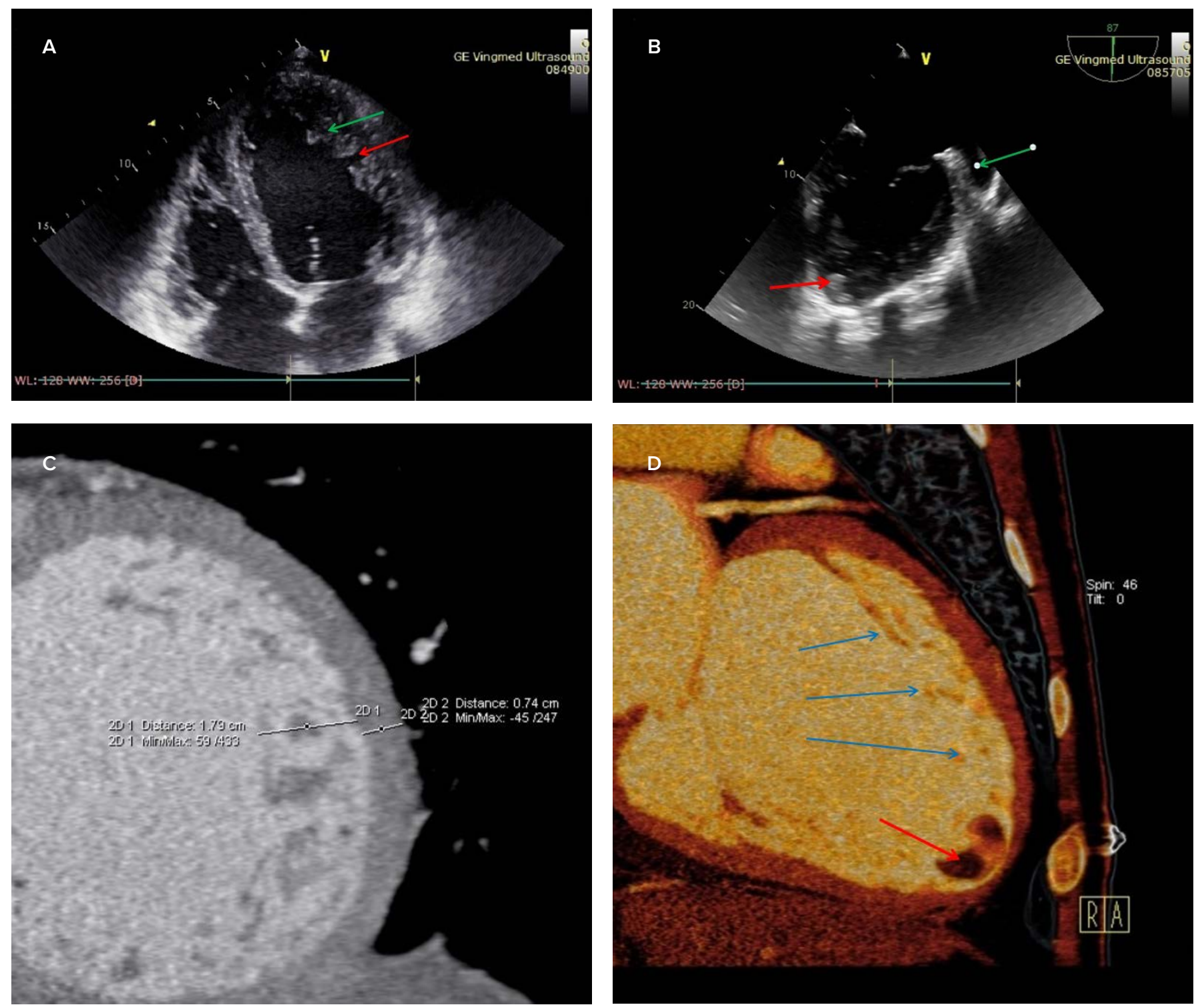

2. Arbustini E, Weidemann F, Hall JL. Left Ventricular Noncompaction: A Distinct Cardiomyopathy or a Trait Shared by Different Cardiac Diseases? J Am Coll Cardiol. 2014;64(17):1840-1850.

3. Stöllberger C, Blazek G, Dobias C, Hanafin A, Wegner C, Finsterer J. Frequency of stroke and embolism in left ventricular hypertrabeculation/ noncompaction. Am J Cardiol. 2011;108(7):1021-1023. 